\title{
Endoscopic management of iatrogenic EUS-related duodenal perforations with over-the-scope clips
}

\section{(1) $\circledast \odot$}

\author{
Authors \\ Hicham El bacha', Frederic Prat ${ }^{2}$ \\ Institutions \\ 1 Medecine B, Hôpital ibn-sina, Mohamed V University, \\ Rabat, Morocco \\ 2 Gastroenterology Department, Hôpital Cochin, Paris, \\ France
}

submitted 19.3.2019

accepted after revision 17.6.2019

Bibliography

DOI https://doi.org/10.1055/a-0967-4718 |

Endoscopy International Open 2020; 08: E59-E63

(c) Georg Thieme Verlag KG Stuttgart · New York elSSN 2196-9736

Corresponding author

Hicham El Bacha, Rue Ait Mhammed Souissi, Rabat, Maroc

Fax: +05 37775856

elbachahicham@hotmail.fr

\section{ABSTRACT}

Background and study aims latrogenic endoscopic ultrasound (EUS) perforations are life-threatening adverse event and to date, surgery has been the main treatment for them. The aim of this study was to assess feasibility and safety of conservative treatment with over-the-scope clips (OTSC).

Patients and methods We performed a retrospective study, including iatrogenic EUS duodenal perforation with conservative endoscopic management from 2011 to August 2018. Patients who initial had surgical management were excluded.

Results In 8504 EUS procedure occurred, 13 perforations occurred $(0.15 \%)$. Eleven patients were included in the study, all women. Mean patient age was 75 years (range $68-88)$. Eighth of 11 perforations $(72.7 \%)$ were due to a radial probe and three of 11 (27.3\%) were due to a curvilinear probe. Eleven procedures (100\%) were performed as diagnostic. Defect size ranged from 10 to $15 \mathrm{~mm}$. All procedures were successful. Three of eleven patients (27\%) had a stay in intensive care unit for less than 72 hours and length of total hospital stay ranged from 3 to 22 days.

Conclusion Conservative endoscopic treatment of latrogenic EUS perforation, with OTSC is feasible, efficient and safe.
Endoscopic ultrasound (EUS) is an essential tool for identification, staging, sampling and follow-up of benign and malignant bilio-pancreatic lesions. Indeed, EUS achieves high performance in choledocholithiasis diagnosis [1] and avoids two-thirds of unnecessary endoscopic retrograde cholangiopancreatography (ERCP) procedures [2]. EUS also has a higher yield than magnetic resonance cholangiopancreatography in diagnostic workup of idiopathic acute pancreatitis assessment [3], and is also the mainstay of exploration of pancreatic solid and cystic masses; finally, more invasive techniques such as EUS-guided fine-needle aspiration/fine-needle biopsy and interventional EUS have expanded considerably recently.

Diagnostic endosonography has traditionally been associated with a very low rate of complications ( $1 \%-2 \%$ ) [4], with perforation, mostly cervical, at less than $0.05 \%$ and associated with risk factors such as esophageal strictures. However, most reports date back from early experiences in which duodenal intubation was much less common than it is today. In addition, many young endoscopists willing to learn EUS have no experience with duodenal intubation with a side or oblique-viewing endoscope and are not necessarily coached by a senior endoscopist as thoroughly as during ERCP training, due to the low expected occurrence of iatrogenic side effects.

Widespread use of EUS makes knowledge and management of these complications mandatory, even during diagnostic procedures.

Perforation remains one of the most common complications in endoscopy and in EUS. Although surgery allows simultaneous treatment of perforation and of an associated biliary or pancreatic disorder, it is invasive, carrying its own morbidity and mortality, especially when undertaken in the context of an emergency. We wanted to assess the feasibility, efficacy, and safety of immediate endoscopic repair of EUS-induced duodenal perforations with over-the-scope clips (OTSC) and report our experience to determine whether this procedure can be recommended in such cases. 

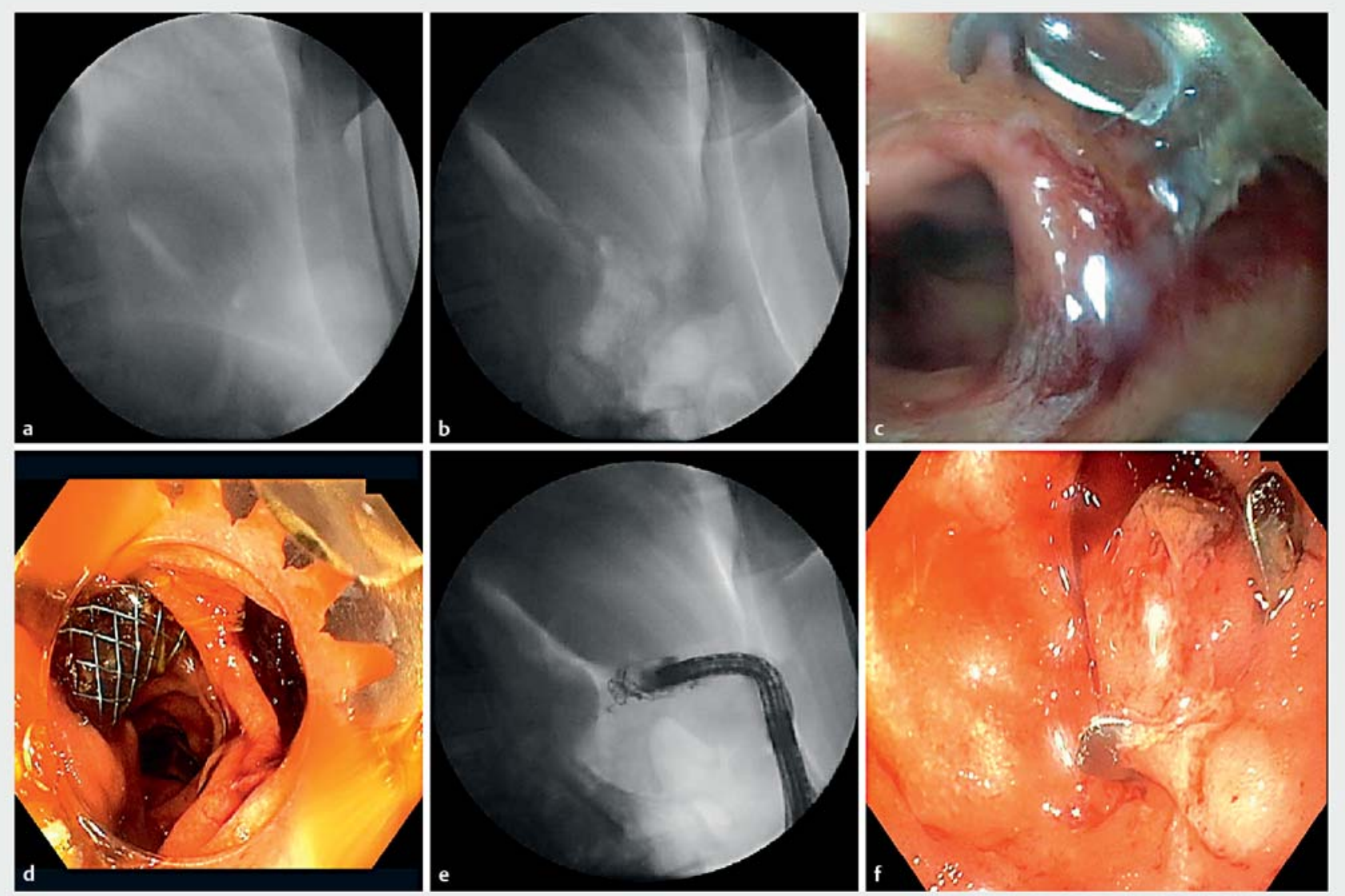

- Fig. 1 Clipping procedure after EUS-related duodenal perforation. a, b Retropneumoperitoneum. c, d Endoscopic view of the perforation. e Perforation closure and injection of contrast showing no leak. $\mathbf{f}$ Endoscopic view of the clip positioning.

\section{Patients and method}

We performed a retrospective study of patients with EUS-related iatrogenic perforation observed in our unit from 2011 to August 2018.

We included all consecutive patients with EUS-related perforation with immediate diagnosis who received conservative endoscopic management. Patients with primary surgical management and conservative, non-interventional management, as well as perforation resulting from an endoscopic intervention (eg endoscopic sphincterotomy, cyst fenestration, etc), were excluded.

Preinterventional clinical data included age, sex, procedure indication, endoscopic report data, perforation location and size. All perforations were diagnosed during the EUS procedure. Once a perforation was diagnosed, air insufflation was shifted to $\mathrm{CO}_{2}$, the EUS scope was retrieved, and a standard $(10-\mathrm{mm}$ diameter, 3.2-mm working channel) forward-viewing endoscope was used to identify and examine the perforation site. The gastroscope was removed, equipped with an OTSC $(11 / 6 \mathrm{~mm}$, type t, Ovesco Endoscopy AG, Tübingen, Germany), and reintroduced and advanced up to the perforation site. Tight closure was assessed endoscopically and by contrast injection ( $\triangleright$ Fig.1). Once the defect was closed, patients were observed overnight with no oral intake, continuous low aspiration tube, and intravenous antibiotics.

Outcome data included technical success, clinical success, length of hospital stay, necessity of transfer to an intensive care unit, adverse events (AE), morbidity and mortality. Technical success was defined as endoscopic perforation management allowing secure positioning of the Ovesco clip with tight sealing of the defect and no visible leak on massive $(50 \mathrm{~mL})$ contrast injection in front of the breach. Clinical success was defined as absence of any post-procedural AE and confirmation of perforation closure on post-op computed tomography (CT) with digestive contrast swallowing, or on repeat endoscopic evaluation.

\section{Results}

Thirteen EUS-induced duodenal perforations occurred during the 7-year study period, among 8504 EUS procedures, or a ratio of $0.15 \%$. All happened during a diagnostic EUS, whether alone or preceding an ERCP. Two patients were excluded, one for a large duodenal tear requiring immediate surgery, the other one for misdiagnosis of perforation leading to early discharge and readmission 24 hours later with peritonitis and emergency 
- Table 1 Study population characteristics.

\begin{tabular}{|c|c|}
\hline & Number \\
\hline Age & 75 (range $68-88$ ) \\
\hline \multicolumn{2}{|l|}{ Sex } \\
\hline - Woman & $11(100 \%)$ \\
\hline \multicolumn{2}{|l|}{ Type endoscope } \\
\hline " Radial & $8(76.7 \%)$ \\
\hline " Curvilinear & $3(27.3 \%)$ \\
\hline \multicolumn{2}{|l|}{ EUS indication } \\
\hline - Diagnostic & $11(100 \%)$ \\
\hline - Pancreatic mass & $5(45 \%)$ \\
\hline - Choledocholithiasis & $2(18 \%)$ \\
\hline - Cholestasis & $2(18 \%)$ \\
\hline " Ampullary tumor & $1(9 \%)$ \\
\hline - Cholangiocarcinoma & $1(9 \%)$ \\
\hline \multicolumn{2}{|l|}{ Perforation location } \\
\hline . UDF & $9(81 \%)$ \\
\hline - Descending part of the duodenum & $1(9 \%)$ \\
\hline . LDF & $1(9 \%)$ \\
\hline \multicolumn{2}{|l|}{ Risk factor } \\
\hline " Stenosis & $3(27.3 \%)$ \\
\hline - Ulcer & $2(18 \%)$ \\
\hline - Angulation & $1(9 \%)$ \\
\hline \multicolumn{2}{|c|}{$\begin{array}{l}\text { EUS, endoscopic ultrasound; UDF, upper duodenal flexure; LDF, lower duo- } \\
\text { denal flexure }\end{array}$} \\
\hline
\end{tabular}

surgery. All but two of 11 included EUS had been initiated by trainees.

- Table 1 shows patient characteristics. All 11 patients were women, mean age of 75 years (range $68-88$ ). Eight of 11 perforations (72.7\%) were due to a radial probe EUS-scope Olympus GF160 (Olympus America, Center Valley, Pennsylvania, United States) and the other three (27.3\%) were due to a curvilinear probe EUS-scope Olympus GF180.Indications for EUS were as follows: assessment of a pancreatic mass in five patients (45\%), suspected choledocholithiasis in two (18\%), exploration of cholestasis in two (18\%), staging of an ampullary tumor in one $(9 \%)$, and of a cholangiocarcinoma the last patient $(9 \%)$.

Perforations were located in the superior part and superior flexure of the duodenum in nine of $11(81 \%)$, in the descending part of the duodenum in one of $11(9 \%)$, or in the inferior duodenal flexure in one of 11 (9\%). Defect size as described in the endoscopic report ranged from 10 to $15 \mathrm{~mm}$.

All clipping procedures resulted in technical as well as a clinical success as defined above. However only nine of 11 had CT evaluation after the procedure, with five having remaining pneumoperitoneum, three a liquid collection of less than $20 \mathrm{~mm}$, and one a suspected persistent contrast leak which was not confirmed thereafter but led to upholding fasting for this patient; no duodenal defect was seen when the patient underwent cholecystectomy 4 days later.

One patient had a second perforation 6 days later due to an ERCP procedure, which was managed conservatively by fasting and antibiotics. One patient had a successful ERCP during the same procedure as EUS immediately before perforation closure with an OTSC. Three of 11 patients (27\%) stayed in an ICU for less than 72 hours and total hospital stay ranged from 3 to 22 days ( $>$ Table 2 ).

\section{Discussion}

Gastrointestinal perforation during EUS is rare. Duodenal perforation occurs in $0.022 \%$ of procedures, according to a German and an international survey conducted from 1982 to $1992[4,5]$. More recently another study reported a $0.86 \%$ duodenal perforation rate [6] in patients with suspected pancreatic cancer. As a consequence of broader EUS indications and of more trainees involved, perforation may have a higher incidence, especially in high-volume academic units.

Perforation may be due to EUS scope design, since EUS scopes are larger than standard gastroscopes at 12.4 to $14.6 \mathrm{~mm}$ vs. 9 to $11 \mathrm{~mm}$ and they are also less flexible and more difficult to maneuver through the proximal duodenum with a side-viewing system, and a longer rigid distal part containing the ultrasound transducer. All these properties lead to partially blind advancement in the digestive tract to reach the second duodenal part, which may cause traumatic lesions, especially in parts with tight angulations. This explains why the majority of perforations occurred in the upper duodenal flexure, right after or at the distal end of the bulb, and they were relatively limited in size, rarely exceeding that of the scope head, or 10 to $15 \mathrm{~mm}$.

As seen in some cases, perforation may also be due to anatomic particularities or alteration, like an ulcer, a tumoral compression or an inflammatory stenosis. In these cases, completing EUS and attempts to pass beyond the stenosis may require difficult maneuvers and induce tension on the duodenal wall, causing the perforation, with risks of a large tear. Surprisingly in this series and despite studies showing EUS safety in elderly patients [7,8], all perforations occurred in elderly women. That may suggest that aging and female sex are possible risk factors for EUS-induced perforation.

Perforation remains the most feared of AEs in endoscopy, because its occurrence can bear serious clinical consequences, especially when it is overlooked or misdiagnosed. Perforation management may require surgery, infers additional costs and raises liability issues with legal consequences. Untreated duodenal perforation may progress to acute peritonitis and septic shock with a high mortality rate. A nationwide survey and a single-center report documented a total of 14 fatal complications due to duodenal tears after EUS $[9,10]$.

Nevertheless, development of endoscopic devices and techniques for endoscopic management of perforations by the 
- Table 2 Perforation clipping details and follow-up.

\begin{tabular}{|c|c|c|c|c|c|c|c|c|}
\hline $\begin{array}{l}\text { Estimated } \\
\text { defect size }\end{array}$ & $\begin{array}{l}\text { Technical } \\
\text { success }\end{array}$ & $\begin{array}{l}\text { ICU } \\
\text { stay }\end{array}$ & Surgery & CT1 & $\mathrm{CT} 2$ & $\begin{array}{l}\text { Follow-up } \\
\text { endoscopy }\end{array}$ & $\begin{array}{l}\text { Delayed adverse } \\
\text { event }\end{array}$ & $\begin{array}{l}\text { Total } \\
\text { LOS }\end{array}$ \\
\hline $10-12 \mathrm{~mm}$ & Yes & No & No & $\begin{array}{l}24 \text { h: PNP, small collec- } \\
\text { tion, no leakage }\end{array}$ & $\begin{array}{l}7 \text { days: } \\
\text { Normal }\end{array}$ & No & No & 12J \\
\hline- & Yes & $48 \mathrm{~h}$ & No & 6 days: small collection & No & $\begin{array}{l}1 \text { month: } \\
\text { Clip still in place }\end{array}$ & No & 22J \\
\hline $15 \mathrm{~mm}$ & Yes & & No & No & No & & No & \\
\hline $15 \mathrm{~mm}$ & $\begin{array}{l}\text { Minimal } \\
\text { leak }\end{array}$ & $72 \mathrm{~h}$ & No & $\begin{array}{l}72 \text { h: leak next to com- } \\
\text { mon bile duct, PNP }\end{array}$ & No & No & No & \\
\hline $8 \mathrm{~mm}$ & Yes & No & No & $\begin{array}{l}24 \text { h: PNP+ retro-PNP } \\
\text { No leak }\end{array}$ & $\begin{array}{l}72 \mathrm{~h}: \\
\text { Normal }\end{array}$ & $\begin{array}{l}45 \text { days: } \\
\text { Clip still in place }\end{array}$ & No & 7] \\
\hline $15 \mathrm{~mm}$ & Yes & No & No & No & No & No & No & 7J \\
\hline $10 \mathrm{~mm}$ & Yes & & No & 72 h: PNP, no leakage & No & No & No & \\
\hline $10-12 \mathrm{~mm}$ & Yes & $24 \mathrm{~h}$ & No & $\begin{array}{l}96 \mathrm{~h} \text { : small collection, } \\
\text { no leak }\end{array}$ & No & $\begin{array}{l}\text { Second perfora- } \\
\text { tion after ERCP }\end{array}$ & $\begin{array}{l}\text { Yes: Second per- } \\
\text { foration after ERCP }\end{array}$ & $8 \mathrm{~J}$ \\
\hline $15 \mathrm{~mm}$ & Yes & No & No & 24 h: PNP, no leakage & No & No & No & 31 \\
\hline $10 \mathrm{~mm}$ & Yes & No & No & 48 h: normal & No & $\begin{array}{l}1 \text { month: } \\
\text { clip still in place }\end{array}$ & No & 4] \\
\hline $10-12 \mathrm{~mm}$ & Yes & No & No & No & No & No & No & 31 \\
\hline
\end{tabular}

endoscopist has completely transformed the way we consider such complications and has allowed more daring and sometimes risk-taking procedures [11].

However, when duodenal perforation occurs during a diagnostic procedure, endoscopic management comes with several caveats attached. First, because delayed management worsens prognosis, the closure procedure must be done immediately, ie within the same anesthesia, preferably after airway intubation and with the aid of a senior endoscopist experienced in endoscopic defect closure $[12,13]$. Second, air insufflation must be immediately switched to low- $\mathrm{CO}_{2}$ flow to reduce peritoneal air insufflation. Rapid management limits air inflation through the defect and switching to $\mathrm{CO}_{2}$ inflation prevents postoperative pain as $\mathrm{CO}_{2}$ is rapidly absorbed. Moreover, rapid defect closure prevents spillage outside the gastrointestinal tract, which would cause infection and peritonitis. Third, standard measures of conservative management must be taken post-op, with patient fasting and broad-spectrum antibiotics covering gramnegative, beta-lactamase-producing and anaerobic germs. Perforation closure with through-the-scope clips (TTS) has been reported in case reports and small case series [14,15] with good outcomes for small defects in the duodenum. However, for large defects where many TTS clips are necessary, the procedure is challenging and the outcome uncertain due to limited space and difficult placement of clips in the duodenum; moreover, TTS endoclips do not grip the duodenum deeply and can easily fall out long before definitive sealing of the defect.

Fully-covered metallic stents (FCSEMS) could also be an alternative to clipping and prevent leakage inside peritoneum.
Yet stent radial expansion can stretch the tear. Moreover, when used for benign conditions, FCSEMS have a high migration rate $62.5 \%$ [16], making stenting a less reliable method.

Ovesco clip (Tubingen, Germany) is an OTSC made from nitinol with self-memory shape; provide a tighter, deeper, and larger grasp of tissue than TTS clips. Ovescoclips have been approved for closure of mural defects up to $18 \mathrm{~mm}$ in size [17] and are considered an effective tool for closure of iatrogenic perforations and their use in the duodenum has previously been reported, although not specifically for EUS-related duodenal punches and perforations [18]. In our study, all procedures resulted in technical and clinical success. Nevertheless, clipping procedure might be tricky, and require some expertise. Handson training may help increase familiarity with OTSC clipping. Some specific precautions are mandatory: a good assessment of defect size and careful introduction of the clip mounted at the tip of the scope through the upper esophagus, to avoid clip migration or disinsertion as well as esophageal tears. Before releasing the clip, the twin grasper forceps need to be completely inside the clip cap to avoid forceps incarceration [19]. After releasing the clip, it is important to assess complete defect closure by injecting a high volume of contrast and then place an aspiration tube. Patients can stay in a standard care unit and, if asymptomatic, be rapidly discharged.

ERCP was performed in one patient during the same procedure as EUS and defect closure was achieved without an additional $A E$, but carrying on with the planned interventional procedure risks enlargement of defect size and a more difficult closure, with continuing insufflation worsening the pneumoperi- 
toneum. A better alternative, apart from a life-threatening biliary emergency, is to continue the procedure after clipping or even better, a few days later [18]. Such was our choice in most patients. The second procedure should indeed be gentle and avoid any tension during scope advancement to prevent tearing around the clip.

\section{Conclusion}

Although bearing a low rate of specific complications, diagnostic EUS is not AE -free and observing proper indications is necessary, especially in elderly patients. Duodenal perforation is a potentially serious $\mathrm{AE}$, but conservative endoscopic treatment with OTSC represents a feasible, efficient, and safe treatment that can prevent surgery in most instances.

\section{Competing interests}

None

\section{References}

[1] Tse F, Liu L, Barkun AN et al. EUS: a meta-analysis of test performance in suspected choledocholithiasis. Gastrointest Endosc 2008; 67: $235-244$

[2] Moutinho-Ribeiro P, Peixoto A, Macedo G. Endoscopic retrograde cholangiopancreatography and endoscopic ultrasound: to be one traveler in converging roads. GE Port J Gastroenterol 2018; 25: 138 145

[3] Wan J, Ouyang Y, Yu C et al. Comparison of EUS with MRCP in idiopathic acute pancreatitis: a systematic review and meta-analysis. Gastrointest Endosc 2018; 87: 1180-1188e9

[4] Jenssen C, Alvarez-Sánchez MV, Napoléon B et al. Diagnostic endoscopic ultrasonography: Assessment of safety and prevention of complications. World J Gastroenterol 2012; 18: 4659-4676

[5] Jenssen C, Faiss S, Nürnberg D. Complications of endoscopic ultrasound and endoscopic ultrasound-guided interventions - results of a survey among German centers. Z Gastroenterol 2008; 46: 1177 1184
[6] Raut CP, Grau AM, Staerkel GA et al. Diagnostic accuracy of endoscopic ultrasound-guided fine-needle aspiration in patients with presumed pancreatic cancer. J Gastrointest Surg 2003; 7: 118-1126

[7] Benson ME, Byrne S, Brust D] et al. EUS and ERCP complication rates are not increased in elderly patients. Dig Dis Sci 2010; 55: 3278 3283

[8] Attila T, Faigel DO. Endoscopic ultrasound in patients over 80 years old. Dig Dis Sci 2011; 56: 3065 - 3071

[9] Lachter J. Fatal complications of endoscopic ultrasonography: A look at 18 cases. Endoscopy 2007; 39: 747-750

[10] Carrara S, Arcidiacono PG, Mezzi G et al. Pancreatic endoscopic ultrasound-guided fine needle aspiration: Complication rate and clinical course in a single centre. Dig Liver Dis 2010; 42: 520 - 523

[11] Paspatis GA, Dumonceau JM, Barthet $M$ et al. Diagnosis and management of iatrogenic endoscopic perforations: European Society of Gastrointestinal Endoscopy (ESGE) Position Statement. Endoscopy 2014; 46: $693-711$

[12] Holmer C, Mallmann CA, Musch MA et al. Surgical management of iatrogenic perforation of the gastrointestinal tract: 15 years of experience in a single center. World J Surg 2017; 41: 1961-1965

[13] Baron TH, Wong Kee Song LM et al. A comprehensive approach to the management of acute endoscopic perforations (with videos). Gastrointest Endosc 2012; 76: 838 - 859

[14] Haider S, Kahaleh M. The use of endoscopic clipping devices in the treatment of iatrogenic duodenal perforation. Gastroenterol Hepatol (NY) 2010; 6: 660-661

[15] Liu Y, Wang D, Li Z. Endoscopic closure for EUS and ERCP related duodenal perforation by endoclips. Gastroenterol Res Pract 2016; 2016: 1051597

[16] Choi WJ, Park J-J, Park J et al. Effects of the temporary placement of a self-expandable metallic stent in benign pyloric stenosis. Gut Liver 2013; 7: 417-422

[17] Banerjee S, Barth BA. ASGE Technology Committee. et al. Endoscopic closure devices. Gastrointest Endosc 2012; 76: 244-251

[18] Angsuwatcharakon P, Prueksapanich P, Kongkam P et al. Efficacy of the Ovesco Clip for closure of endoscope related perforations. Diagn Ther Endosc 2016; 2016: 9371878

[19] Brodie M, Gupta N, Jonnalagadda S. Failed attempt at duodenal perforation closure with over-the-scope clip. Gastrointest Endosc 2015; 81: 1271-1272 